\title{
COMMENTARY
}

\section{Threading a pathway through the forest of mood and personality disorders}

\author{
Peter Tyrer (1) \\ COMMENTARY ON... Bordering on the bipolar ${ }^{\dagger}$
}

\begin{abstract}
Peter Tyrer is Emeritus Professor of Community Psychiatry at the Centre for Psychiatry, Imperial College, London, and Honorary Professor in Psychiatry at the University of Nottingham, UK.

Correspondence Professor Peter Tyrer, Imperial College, 7th Floor, Commonwealth Building,

Hammersmith Hospital, London W12 ONN, UK.

Email: p.tyrer@imperial.ac.uk
\end{abstract}

First received 29 Aug 2019

Final revision 16 Sep 2019

Accepted 18 Sep 2019

Copyright and usage

(C) The Author 2019

\footnotetext{
${ }^{\dagger}$ See this issue.
}

\section{SUMMARY}

The classification of mood and personality disorders has become unnecessarily complicated. It has become bogged down by well-meaning but unhelpful subcategories that puzzle the will of clinicians to make useful judgements. The answer is to think of bipolar, depressive and personality disorders as each constituting a spectrum of severity and not to be too preoccupied with individual labels. It would also be useful to avoid the diagnostic chimera of borderline personality disorder, a condition that defies proper classification.

\section{DECLARATION OF INTEREST}

P. T. was the Chair of the World Health Organization's ICD-11 working group for the revision of the classification of personality disorders, 2010-2017.

\section{KEYWORDS}

Bipolar affective disorders; borderline personality disorder; depressive disorders.

Luty (2019) summarises the present status, some may describe it as chaos, in the classification of affective and personality disorders. We are now getting increasingly bogged down in minutiae. Every clinician will realise that, when a diagnosis critically depends on the exact duration of a recalled symptom or behaviour, down to the level of hours, we are getting closer to Agatha Christie than Emil Kraepelin. So if raised mood disturbance lasts for a few hours we have borderline personality disorder, if it extends for 4-6 days it becomes bipolar II affective disorder, but then one extra day makes it bipolar I (hypomania), not forgetting that if it yo-yoes up and down without ever crossing these boundaries, it becomes cyclothymia. Welcome to the temporal pinball machine of mood - though has it taken the important issue of weekends into account?

But you can rest assured that, despite these formal definitions, there is no consensus here. In a series of articles on bipolar disorder in a recent issue of The Canadian Journal of Psychiatry, Vieta (2019) trumpets, 'The inclusion of bipolar II disorder as a subtype of bipolar illness in the DSM- $I V$ is probably, from a clinical perspective, the most important change in the classification of mental disorders over the past 25 years'. Robert Post (2019) is not so sure but still likes the idea and adds a new category: 'It is not clear what would be gained by dropping bipolar II, and much could be lost. I suggest, instead, that we should have it both ways. Add some further specifics, clarifications, and quantitation, but keep the general distinctions of bipolar disorder not otherwise specified (bipolar NOS), bipolar II, and bipolar I'.

But Gin Malhi and his colleagues will have none of it. They propose 'the abandonment of bipolar I and bipolar II as diagnostic categories and suggest an evidence-based and pragmatic dimensional approach to the diagnosis of mania within the single disorder entity of "bipolar disorder" (Malhi 2019). To complete the picture, Andrew Nierenberg (2019) perches delicately on the fence and asks (and answers), 'Is bipolar II a valid category or is it a spectrum of bipolar disorder? Yes. Or maybe'.

We are used to healthy disagreements in psychiatry but these are profound ones and expressed by acknowledged experts. Yet at least they do not demonstrate what I call the 'Boreham conundrum', named after Judge Leslie Boreham in the Yorkshire Ripper case, who was so flabbergasted by the agreement of four psychiatrists, all independently making the same diagnosis of paranoid schizophrenia, that he scratched his head, concluded they must have been deceived and so ignored their evidence entirely.

\section{What is the solution?}

My solution is very simple (Table 1). The three fields of bipolar, depressive and personality disorders each constitute a single dimension - spectrum if you likebetween no pathology and very serious disruption. 
TABLE 1 A spectrum classification of bipolar, depressive and personality disorder

\begin{tabular}{|c|c|c|c|c|}
\hline Spectrum type & Subsyndromal & Mild & Moderate & Severe \\
\hline Bipolar & $\begin{array}{l}\text { Not a formal disorder (but may include } \\
\text { cyclothymia) }\end{array}$ & $\begin{array}{l}\text { Brief periods of elevated mood, with } \\
\text { longer depressive ones } \\
\text { (equivalent to bipolar II disorder) }\end{array}$ & $\begin{array}{l}\text { Longer or more severe episodes of } \\
\text { elevated and depressed mood } \\
\text { (equivalent to mania) }\end{array}$ & Unequivocal bipolar disorder \\
\hline $\begin{array}{l}\text { Depressive (often } \\
\text { with admixture } \\
\text { of anxiety) }\end{array}$ & $\begin{array}{l}\text { Falling short of disorder but still creating } \\
\text { significant impairment }\end{array}$ & $\begin{array}{l}\text { Long periods of depression leading to } \\
\text { some, but not severe, functional } \\
\text { impairment (equivalent to } \\
\text { dysthymia) }\end{array}$ & $\begin{array}{l}\text { Clear episodes of moderate } \\
\text { depression (equivalent to major } \\
\text { depressive episode) }\end{array}$ & $\begin{array}{l}\text { Depressive disorder with } \\
\text { melancholia }\end{array}$ \\
\hline Personality disorder & $\begin{array}{l}\text { Personality difficulty (not a disorder but a } \\
\text { Z-code in ICD-11), with personality } \\
\text { dysfunction only in certain settings }\end{array}$ & $\begin{array}{l}\text { Personality dysfunction is persistent } \\
\text { but does not prevent normal } \\
\text { functioning }\end{array}$ & $\begin{array}{l}\text { Persistent interpersonal and self } \\
\text { pathology, with disruption in } \\
\text { personal, social and } \\
\text { occupational areas }\end{array}$ & $\begin{array}{l}\text { Severe personality } \\
\text { disruption, with high } \\
\text { risk of harm to self or } \\
\text { others }\end{array}$ \\
\hline
\end{tabular}

A dimension cannot stand alone as a diagnosis, so anchor points are needed at different positions on the spectrum that have clear definitions and, if they are to be useful, guide treatment.

The table indicates severity of disorder primarily; the duration of symptoms is less important. As Malhi et al (2019) comment in regard to bipolar disorder, 'at any time, factors related to severity can override those pertaining to duration'.

This is clinical common sense. I used to look after an unusual patient who had very brief periods of severe disturbance, often lasting less than $48 \mathrm{~h}$, and during this time she would take off most, if not all, her clothes, ogle the men on building sites close by and rush around like a wild animal. She undoubtedly had manic episodes but would not have met the current criteria for bipolar I disorder. By concentrating on the severity of the condition this error is prevented.

The only spectrum in Table 1 that has been accepted in ICD-11 is the personality one (Tyrer 2015). All the existing categories of personality disorder have been discarded from the 11th revision, as, despite their popularity in lay circles, they have no scientific standing (Livesley 2013). Most people have some personality disturbance, and although it is at the lower end of the spectrum, the subsyndromal condition of personality difficulty is still associated with significant pathology and dysfunction (Karukivi 2017). Severe personality disorder is diagnosed only when there is a high risk of harm to self or others (although this is not 'automatic' as Luty states).

The personality pathology formerly described in categories has been subsumed into five domain traits in ICD-11: negative affectivity, detachment, anankastia, disinhibition and dissociality. These qualify the level of severity but are not diagnoses in their own right (Tyrer 2019).

\section{The place of borderline personality disorder}

But where is borderline personality disorder in my table? It is absent, for a good reason. 'Borderline' is a fractious yet seductive label, a Mata Hari inveigling its way into both ICD and DSM diagnoses of personality disorder without ever being asked. Yet it has dominated the field of personality disorder. To aptly misquote Shakespeare, it doth bestride the narrow world like a colossus while other personality groups peep about under its huge legs like dishonourable knaves'.

As Luty points out, many of the symptoms and behaviours of borderline personality disorder overlap with mood disorders of all types, but particularly with bipolar II disorder. This is the chameleonlike problem of 'borderline'. Its only accurate property is its name: it borders on almost every psychiatric disorder and so can imitate them effortlessly.

But you do not need to use the term. Following pressure from a group who want to preserve the colossus of borderline from destruction, the possibility of a 'borderline pattern descriptor' (note the words - it is not a diagnosis) has been added as an optional qualifier in ICD-11, but only after severity has been specified. Most of this pathology would be classified within the domains of negative affectivity, disinhibition and dissociality, and this may help to identify better groupings.

In deciding whether to diagnose a patient on the bipolar or personality spectrum it is very important to recognise, as Luty points out, that comorbidity of personality and mental state pathology is very common. It is unfortunate that the diagnostic axis of personality disorder was abolished in DSM-5, because its retention would have prevented the danger of forgetting about personality disturbance (Newton-Howes 2015). Perhaps the most important task of the clinician is to decide which spectrum a particular patient should be placed on, as the treatment varies greatly across all three.

\section{References}

Karukivi M, Vahlberg T, Horjamo K, et al (2017) Clinical importance of personality difficulties: diagnostically sub-threshold personality disorders. BMC Psychiatry, 17: 16.

Livesley J (2013) The DSM-5 personality disorder proposal and future directions in the diagnostic classification of personality disorder. Psychopathology, 46: 207-16. 
Luty J (2019) Bordering on the bipolar: a review of criteria for ICD-11 and DSM-5 persistent mood disorders. BJPsych Advances, this issue.

Malhi GS, Outhred T, Irwin L (2019) Bipolar II disorder is a myth. Canadian Journal of Psychiatry, 64: 531-6.

Newton-Howes G, Mulder R, Tyrer P (2015) Diagnostic neglect: the potential impact of losing a separate axis for personality disorder. British Journal of Psychiatry, 206: 355-6.

Nierenberg AA (2019) Bipolar II disorder is NOT a myth. Canadian Journal of Psychiatry, 64: 537-40.
Post RM (2019) Bipolar II disorder: not so sure it is time for something new. Canadian Journal of Psychiatry, 64: 544-7.

Tyrer P, Reed GM, Crawford MJ (2015) Classification, assessment, prevalence, and effect of personality disorder. Lancet, 385: 717-26.

Tyrer P, Mulder R, Kim YR, et al (2019) The development of the ICD-11 classification of personality disorders: an amalgam of science, pragmatism, and politics. Annual Review of Clinical Psychology, 15: 481-502.

Vieta E (2019) Bipolar II disorder: frequent, valid, and reliable. Canadian Journal of Psychiatry, 64: 541-3. 